\title{
Solid phase microextraction procedure for the determination of alkylphenols in water by on-fiber derivatization with N-tert-butyl-dimethylsilyl-N-methyltrifluoroacetamide
}

\author{
Yi-Ping Pan, Shih-Wei Tsai* \\ Institute of Environmental Health, College of Public Health, National Taiwan University, No. 17, Xuzhou Road, Taipei 100, Taiwan
}

\section{A R T I C L E I N F O}

Article history:

Received 7 March 2008

Received in revised form

21 June 2008

Accepted 24 June 2008

Published on line 1 July 2008

Keywords:

Solid phase microextraction

$\mathrm{N}$-tert-butyl-dimethylsilyl-N-

methyltrifluoroacetamide

Alkylphenols

Gas chromatography

\begin{abstract}
A B S T R A C T
The solid phase microextraction (SPME) technique with on-fiber derivatization was evaluated for the analysis of alkylphenols (APs), including 4-tert-octylphenol (4-t-OP), technical nonylphenol isomers (t-NPs) and 4-nonylphenol (4-NP), in water. The $85 \mu \mathrm{m}$ polyacrylate (PA) fiber was used and a two-step sample preparation procedure was established. In the first step, water sample of $2 \mathrm{~mL}$ was placed in a $4 \mathrm{~mL}$ PTFE-capped glass vial. Headspace extraction of APs in water was then performed under $65^{\circ} \mathrm{C}$ for $30 \mathrm{~min}$ with $800 \mathrm{rpm}$ magnetic stirring and the addition of $5 \%$ of sodium chloride. In the second step, the SPME fiber was placed in another $4 \mathrm{~mL}$ vial, which contained $100 \mu \mathrm{L}$ of $\mathrm{N}$-tert-butyl-dimethylsilyl-Nmethyltrifluoroacetamide (MTBSTFA) with $1 \%$ tert-butyl-dimethylchlorosilane (TBDMCS). Headspace extraction of MTBSTFA and on-fiber derivatization with APs were performed at $45^{\circ} \mathrm{C}$ for $10 \mathrm{~min}$. Gas chromatography/mass spectrometry (GC/MS) was used for the analysis of derivatives formed on-fiber. The adsorption-time profiles were also examined. The precision, accuracy and method detection limits (MDLs) for the analysis of all the APs were evaluated with spiked water samples, including detergent water, chlorinated tap water, and lake water. The relative standard deviations were all less than $10 \%$ and the accuracies were $100 \pm 15 \%$. With $2 \mathrm{~mL}$ of water sample, MDLs were in the range of $1.58-3.85 \mathrm{ng} \mathrm{L}^{-1}$. Compared with other techniques, the study described here provided a simple, fast and reliable method for the analysis of APs in water.
\end{abstract}

(C) 2008 Elsevier B.V. All rights reserved.

\section{Introduction}

Alkylphenols (APs) are man-made chemicals which are used primarily to produce alkylphenol ethoxylates (APEs) [1]. APs and APEs are major components of non-ionic surfactants which account for roughly $40 \%$ of worldwide surfactant market [2]. The most commercially important alkylphenols are nonylphenol (NP) and octylphenol (OP) which exist in different forms or isomers. For example, technical nonylphenol (t-NP) is a degradation product of alkylphenol polyethoxylates
(APEOs) which are used as non-ionic surfactants in detergents, paints, herbicides, pesticides and plastics [2]. In 1996, the world annual production of alkylphenol polyethoxylates (APEOs) was approximately 500,000 tons [2].

NP and OP have attracted much scientific attention because of their estrogenic effects and ability to bioaccumulate in aquatic organisms [3]. Because they mimic hormones, APs can interact with the estrogen receptor as endocrine-disrupting chemicals (EDCs), and cause a variety of adverse effects in ecology [4-7]. It has been reported that human exposures to

\footnotetext{
* Corresponding author. Tel.: +886 23322 8097; fax: +886 223516289.

E-mail address: shihweitsai@ntu.edu.tw (S.-W. Tsai). 
low levels of APs via daily activities may be associated with health risks [8]. The European Union has recently legislated limitations (Directive 2003/53/EC) for the use of APEs and APs in industrial applications [9]. The US Environmental Protection Agency (USEPA) has legislated an aquatic-life, water-quality criterion of NP for freshwater and saltwater $[10,11]$.

Many researchers have reported on a wide occurrence of APs in environment matrices, including air [12], surface water [13], and sediment [14]. The increased awareness of the presence of APs in the environment has led to an interest in the trace analysis of these compounds. For the determination of APs in the environment, either direct measurements of the analytes or derivatizations of the APs before analysis have been applied [12-14]. However, determination of APs from environmental samples at low concentrations is still a challenging task [15].

Traditional techniques for the extraction and concentration of APs from environmental samples, including liquid-liquid extraction (LLE) and solid phase extraction (SPE), often need large volumes of samples and solvents [12-14]. The main drawbacks attributed to sample pretreatment have been the time consuming and complex procedures.

Other streamlined approach was an extraction technique called solid phase microextraction (SPME), developed by Pawliszyn [16,17], which presents many advantages over conventional analytical methods. This method recommends combining sampling, preconcentration, and direct transfer of the analytes into a standard gas chromatograph (GC) system [18]. It has been reported that for water samples the hydroxylgroup containing endocrine disruptors such as APs can be determined by the technique of SPME without derivatization $[19,20]$. However, several problems usually occurred with trace level analysis in environmental samples. For example, peak tailing due to interaction of the analytes with active sites in the analytical column might occur [11]. Therefore, it was suggested that compounds such as APs which contain polar groups in their structures should be derivatized before the analysis with GC to improve the quality and sensitivity of separations [21]. A wide range of reagents have been reported in the literatures for the APs derivatizations, including methylation [22], acetylation [23], and silylation [24].

As mentioned above, SPME procedures without derivatization have been used to determine APs in water samples $[19,20,25]$. SPME procedures with derivatizations have also been developed for the measurements of APs [15,26]. However, all these SPME procedures operated by direct sample immersions while the SPME fiber could be contaminated easily [27]. Therefore, if trace level of APs in water sample can be detected by the headspace extraction of SPME, the background adsorption and matrix effects from direct sample immersions could be reduced [27].

As for the derivatizaton, silylation with bis(trimethylsilyl)trifluoroacetamide (BSTFA) has been performed to determine APs in water sample $[15,26]$. However, it was reported that silyl derivatives had limited stability with regard to hydrolysis while moisture content could affect the derivatization process [28].

Since all the current available methods had drawbacks regarding the measurements of trace level APs in water samples, the purpose of the study was to develop a new sensitive and rapid analytical technique. In this research, the SPME procedure with headspace extraction was performed to reduce background adsorption and matrix effects. Derivatization with $\mathrm{N}$-tert-butyldimethylsilyl-N-methyltrifluoroacetamide (MTBSTFA), which results in the formation of tert-butyldimethylsilyl (t-BDMS) derivatives, has been reported to be less sensitive to hydrolysis [11,29]. Therefore, MTBSTFA was used as the derivatizing agent to enhance stability. Effects of experimental parameters on both headspace SPME and on-fiber derivatization were investigated as well.

\section{Experimental}

\subsection{Materials}

Purity grade $\geq 98 \%$ 4-nonylphenol (4-NP), technical nonylphenol isomers (t-NPs, purity drage $\geq 94 \%$ ) and HPLC grade ethanol (purity $\geq 99.9 \%$ ) were obtained from Riedel de Häen (Seelze, Germany). 4-t-Octylphenol (4-t-OP, purity grade $\geq 98.7 \%$ ) and the derivatization reagent MTBSTFA with 1\% TBDMCS was purchased from Aldrich (Milwaukee, WI, USA). Sodium chloride $(\mathrm{NaCl}$, purity grade $\geq 99.5 \%$ ) was from Showa (Tokyo, Japan). Deionized water was from the Barnstead NANOpure Infinity Water Purification Systems (Dubuque, IA, USA). Stock standard solutions of each AP were prepared by dissolving the compounds in ethanol and were stored at $4{ }^{\circ} \mathrm{C}$. The stability of the stock solutions was around 9 months [30], and working standard solution was freshly prepared by dilution in water daily, and were also stored at $4{ }^{\circ} \mathrm{C}$. All SPME fibers, holders and molecular sieves were from Supelco (St. Louis, MO, USA).

\subsection{Instrumentation}

All analyses were performed on a Hewlett-Packard 6890 gas chromatography equipped with a 5972 mass-selective detector from Angilent (Santa Clara, CA, USA). Rtx-5MS ( $60 \mathrm{~m} \times 0.25 \mathrm{~mm}$ i.d., $0.25 \mu \mathrm{m}$ film thickness) capillary column from Restek (Bellefonte, PA, USA) was used. The transfer temperature was set at $310^{\circ} \mathrm{C}$. The injection port temperature was $280^{\circ} \mathrm{C}$ with splitless mode and a $0.75 \mathrm{~mm}$ i.d. SPME injection sleeve liner from Supelco (St. Louis, MO, USA) was used. The temperature program was a solvent delay of $1 \mathrm{~min}$ at $100^{\circ} \mathrm{C}$, increasing to $290^{\circ} \mathrm{C}$ at a rate of $19^{\circ} \mathrm{C} \mathrm{min}^{-1}$ and held for 4 min. Helium for GC/MS was $99.9995 \%$ supplied from Sanfu (Taipei, Taiwan). All the work was carried out in constant flow mode set at $1.0 \mathrm{~mL} \mathrm{~min}^{-1}$. Qualitative and quantitative analyses were operated in the selected ion monitoring (SIM) mode.

\subsection{SPME fiber selections}

Headspace extraction of APs in water by SPME was first performed followed by the derivatization procedure with MTBSTFA. Factors that might affect the optimization of aqueous phase extractions, such as fiber coatings, extraction conditions, derivatization procedure, and desorption conditions [16], were investigated. APs of fixed concentration $\left(1 \mu \mathrm{gL}^{-1}\right)$ were prepared and $2 \mathrm{~mL}$ of each solution was placed in a $4 \mathrm{~mL}$ PTFE-capped glass vial. 
Among the commercially available SPME fibers, polyacrylate (PA) and polydimethoxysilane-divinylbenzene (PDMS-DVB) were primarily used for the extraction of polar compounds, while polydimethoxysilane (PDMS) fibers were used for the enrichment of non-polar compounds [16]. Since APs belong to a more polar class, the maximum extraction yields would be expected to be obtainable using PA or PDMB-DVB [31]. Therefore, both $85 \mu \mathrm{m}$ PA and $65 \mu \mathrm{m}$ PDMS-DVB fibers were examined to establish one that would provide the highest loading and stability retention characteristics.

\subsection{SPME procedures for extracting APs}

Besides fiber selections, both extraction time and extraction temperature are critical parameters in the SPME sampling process. Different periods of time, including 5, 10, 20, 30, 40, and $50 \mathrm{~min}$, for headspace extraction of APs were performed to get the adsorption-time profile. Effects of different temperature, including 25,45 , and $65^{\circ} \mathrm{C}$, on extraction were also evaluated. The effect of salt adding was investigated at concentrations of $\mathrm{NaCl}$ equaled $0 \%, 5 \%, 10 \%$, and $20 \%$. Effects of agitation were determined at the stirring rates of $0,400,800$, and $1100 \mathrm{rpm}$.

\subsection{SPME procedures for on-fiber derivatization}

After the extraction of APs, the SPME fiber was placed in a $4 \mathrm{~mL}$ vial, which contained $100 \mu \mathrm{L}$ of derivatization reagent. Different periods of time, including 3, 5, 10, 20, and $30 \mathrm{~min}$, for the headspace extraction of MTBSTFA were performed. Different temperatures $\left(25,45\right.$, and $\left.65^{\circ} \mathrm{C}\right)$ were evaluated to obtain the highest efficiency for the on-fiber derivatization. Afterwards, the fiber was inserted into the GC injector for thermal desorption. To ensure the desorption was complete, different desorption time $(2,3,4$, and $5 \mathrm{~min})$ and temperatures $(260,270$, 280 , and $290^{\circ} \mathrm{C}$ ) were examined. All the experiments were performed in triplicates. For successive analysis of samples, the SPME fiber was always first heated in the GC injector, and a blank run was performed to make sure the fiber was clean, as well as to avoid the carry-over effects.

\subsection{Calibration and quantitations}

APs at six concentration levels ranging from 0.005 to $1.0 \mu \mathrm{gL}^{-1}$ were prepared. The APs derivatives, i.e. the t-BDMS deriva- tives, were quantified. To determine the precision and accuracy, spiked real water samples $\left(0.01\right.$ and $\left.0.2 \mu \mathrm{gL}^{-1}\right)$, including detergent water, chlorinated tap water, and lake water, were analyzed seven times, respectively. The water samples were first examined to be free of APs before they were spiked. For detergent water, dish-washing detergent purchased from a local supermarket was first diluted to $6.7 \mathrm{gL}^{-1}$ with deionized water before the analysis [32]. For lake water, samples were collected using prerinsed glass bottles. After collection, the lake water samples were shipped to the laboratory on ice and the analysis followed within one day.

For the procedures mentioned above, two SPME fibers each from two different batches were used to evaluate the interbatch reproducibility. For each spiked sample, one of the fibers was used to analyze the sample for three times while the second fiber was used to analyze the sample for four times. The relative standard deviation (R.S.D.) and accuracy were then calculated. Three APs (4-t-OP, t-NPs and 4-NP), each at a concentration of $0.005 \mu \mathrm{gL}^{-1}$, were analyzed seven times, respectively to determine the method detection limits (MDLs) based on the calculation procedures suggested by the USEPA (where MDL = standard deviation of replicate analyse $\times$ Student's $t$ value for the $99 \%$ confidence level with $n-1$ degrees of freedom) [33].

\section{Results and discussion}

\subsection{Fiber selection}

Among commercially available SPME fibers, the PA phase was usually recommended for polar compounds due to the higher affinity for phenolic groups [34]. It was reported that PDMS-DVB can be used to extract polar compounds as well [35]. Since APs belong to a more polar class, the abilities of APs and $t-B D M S$ derivatives extractions by the PA and PDMS-DVB fibers were evaluated in this study.

As shown in Table 1 , headspace extractions of $1 \mu \mathrm{gL}^{-1}$ APs solution for $30 \mathrm{~min}$ at $25^{\circ} \mathrm{C}$ were performed with PA and PDMS-DVB fiber. Headspace extractions of $100 \mu \mathrm{L}$ MTBSTFA reagent for $10 \mathrm{~min}$ were also performed to examine fiber's ability of loading t-BDMS derivatives. Table 1 shows that higher relative area response was observed from the extraction of $85 \mu \mathrm{m}$ PA fiber for both APs and the t-BDMS derivatives (GC/MS was used for the analysis with SIM mode). Therefore, the $85 \mu \mathrm{m}$ PA fiber was selected in this research.

Table 1 - Loading abilities of fibers for APs and t-BDMS derivatives

\begin{tabular}{|c|c|c|c|c|c|c|}
\hline \multirow[t]{3}{*}{ Fiber types } & \multicolumn{6}{|c|}{ Relative peak areas ${ }^{a}$} \\
\hline & \multicolumn{3}{|c|}{$\mathrm{APs}^{\mathrm{b}}$} & \multicolumn{3}{|c|}{ t-BDMS derivatives ${ }^{c}$} \\
\hline & $4-\mathrm{t}-\mathrm{OP}$ & t-NPs & 4-NP & $4-\mathrm{t}-\mathrm{OP}$ & t-NPs & 4-NP \\
\hline PA $85 \mu \mathrm{m}$ & 56894 & 4870 & 9548 & 242413 & 30915 & 48337 \\
\hline PDMS/DVB $65 \mu \mathrm{m}$ & 16480 & 1523 & 3721 & 82640 & 8493 & 20983 \\
\hline
\end{tabular}


The condition for thermal desorption of the SPME fiber was also determined. At temperature of $280^{\circ} \mathrm{C}$, the desorption efficiency was found to be $99.96 \%$ when the desorption time was $3 \mathrm{~min}$.

\subsection{SPME procedures for extracting APs}

After the PA fiber was selected, different periods of time, including 5, 10, 20,30,40, and $50 \mathrm{~min}$, were used for the headspace extraction of APs. The adsorption-time profiles showed that the amounts of all APs extracted increased as the extraction time increased, and the equilibrium time for t-NPs, 4-NP and 4-t-OP were all approximately $30 \mathrm{~min}$. Therefore, 30 min was selected for the headspace extraction of APs.

Besides the extraction time, effects of temperatures, including 25,45 , and $65^{\circ} \mathrm{C}$, on extractions were also evaluated. It was observed that the extraction efficiencies for all the APs seemed to be increased as the temperature increased above room temperature. However, the amounts of APs extracted began to decrease when the temperatures were higher than $65^{\circ} \mathrm{C}$. A possible explanation for this result was that the distribution constant on the fiber might diminish at higher temperature [16]. Therefore, $65^{\circ} \mathrm{C}$ was selected for the headspace extraction of APs in this study.

For many organic analytes, aqueous solubility decreased with increasing ionic strength and the partitioning from the aqueous solution to the headspace might be improved [16]. Agitation might also affect the equilibration time of aqueous samples [16]. The effects of agitation (including 0, 400, 800, and $1100 \mathrm{rpm}$ ) and ion strength (including 0\%, 5\%, 10\%, and $20 \%$ of $\mathrm{NaCl}$ ) on the extractions of APs were investigated in this study. As shown in Figs. 1 and 2, 5\% of salt adding and $800 \mathrm{rpm}$ of stirring were chosen for the following validations since higher efficiencies could be reached.

\subsection{SPME procedures for on-fiber derivatization}

After the conditions for headspace extraction of APs were established, effects of different procedures on the amounts of $t$-BDMS derivatives formed on-fiber were investigated. The

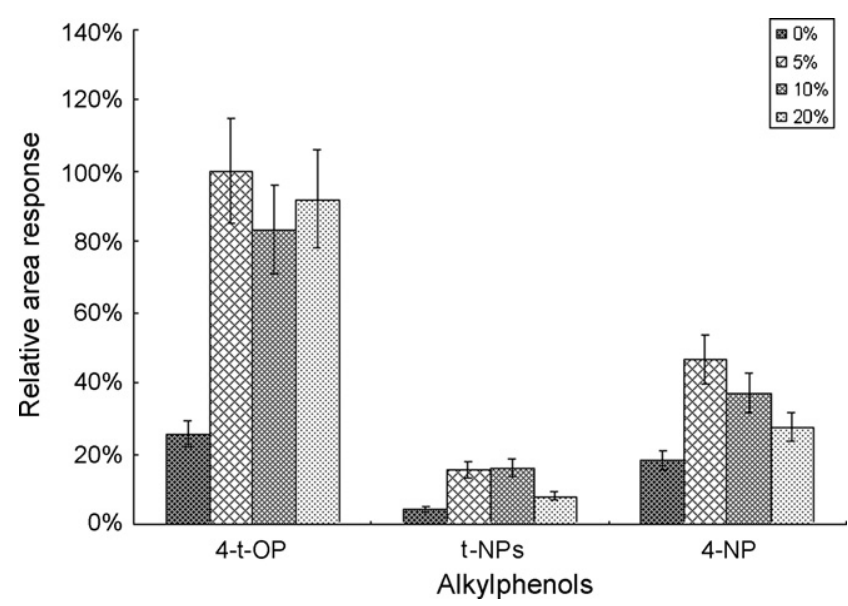

Fig. 1 - Effects of $\mathrm{NaCl}$ concentrations, including $0 \%, 5 \%$, $10 \%$, and $20 \%$, on the extraction efficiencies of APs. Sample volume was $2 \mathrm{~mL}$ and spiking level was $1 \mu \mathrm{g} \mathrm{L}^{-1}$.

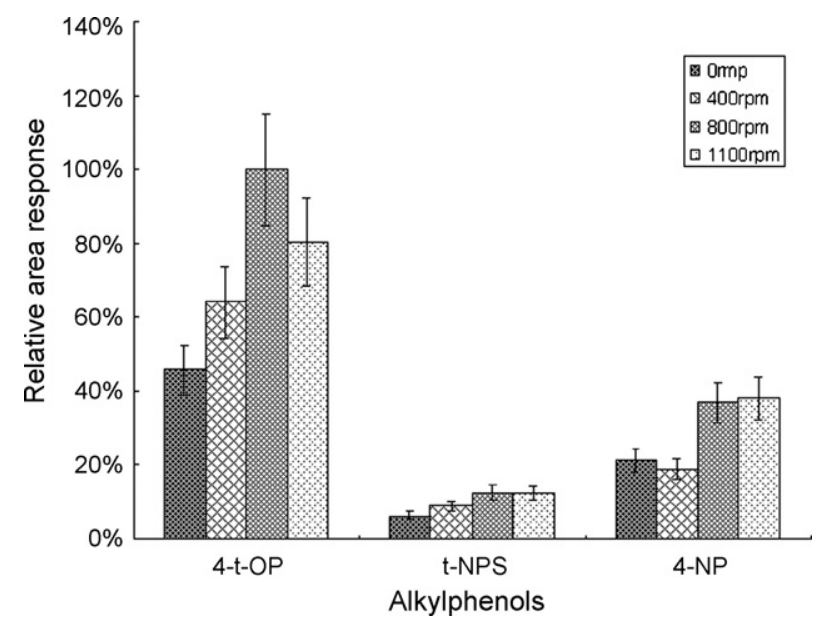

Fig. 2 - Effects of stirring rate, including 0, 400, 800, and $1100 \mathrm{rpm}$, on the extraction efficiencies of APs. Sample volume was $2 \mathrm{~mL}$ and spiking level was $1 \mu \mathrm{g} \mathrm{L}^{-1}$.

APs were first headspace extracted by the SPME fiber. Then, the fiber was placed in a $4 \mathrm{~mL}$ vial which contained $100 \mu \mathrm{L}$ of derivatization reagent. Different periods of time, including 3, $5,10,20$, and $30 \mathrm{~min}$, for the headspace extraction of MTBSTFA were used. Different temperatures, including 25,45 , and $65^{\circ} \mathrm{C}$ were also employed during the extractions to obtain the highest efficiency for the on-fiber derivatization.

It was observed that the time profile reached equilibrium around $10 \mathrm{~min}$ for all the derivatives, while the best response could be obtained when the temperature was $45^{\circ} \mathrm{C}$. When the temperatures were higher than $45^{\circ} \mathrm{C}$, the amounts of t-BDMS derivatives formed began to decrease. Another concern was the fiber coating might be damaged at high derivatization temperature due to the derivatization reagent vapor might slightly dissolve the coating [20]. Therefore, $45^{\circ} \mathrm{C}$ for derivatization was selected in the following experiments.

\subsection{Method validations}

Fig. 3 shows a typical GC/MS chromatogram of the t-BDMS derivatives formed on-fiber from spiked sample. APs in water were first headspace extracted by the SPME fiber. Afterwards, the SPME fiber was placed in a $4 \mathrm{~mL}$ vial which contained $100 \mu \mathrm{L}$ MTBSTFA for headspace extraction and on-fiber derivatization. As shown in Fig. 3, temperature programming of the instrument caused the baseline drifted steadily upwards before $13 \mathrm{~min}$. The $\mathrm{m} / \mathrm{z}=249$ was set for the SIM mode before $13 \mathrm{~min}$. After $13 \mathrm{~min}$, the $\mathrm{m} / \mathrm{z}=277$. This explained the difference of the baseline in the chromatogram.

It has been reported that many silyl derivatives have limited stability due to hydrolysis [11,29]. One of the major advantages in current study was the use of MTBSTFA with 1\% TBDMCS for derivatization. The derivative, $t$-BDMS, is considered stable even when it is moist [11,29]. In addition, the derivatives formed have very favorable EI mass spectra which will further facilitate the low level detections [36]. Further experiments showed that large peak of MTBSTFA was still observed after reaction when the spiking level of APs was as high as $1 \mathrm{mgL}^{-1}$. Therefore, increas- 
Table 2 - Precision and accuracy in chlorinated tap water, detergent water, and lake water ${ }^{\mathrm{a}}$

\begin{tabular}{|c|c|c|c|c|c|c|}
\hline & \multicolumn{2}{|c|}{ Chlorinated tap water } & \multicolumn{2}{|c|}{ Detergent water } & \multicolumn{2}{|c|}{ Lake water } \\
\hline & $0.01 \mu g L^{-1}$ & $0.2 \mu g L^{-1}$ & $0.01 \mu g L^{-1}$ & $0.2 \mu g L^{-1}$ & $0.01 \mu g L^{-1}$ & $0.2 \mu g L^{-1}$ \\
\hline 4-t-OP & $110(8.1)^{b}$ & $90(5.1)$ & $115(7.1)$ & $105(6.6)$ & $97(9.6)$ & $88(4.0)$ \\
\hline t-NPs & $103(7.0)$ & $96(3.7)$ & $90(8.0)$ & $98(4.1)$ & $91(9.4)$ & $115(5.2)$ \\
\hline 4-NP & $103(6.2)$ & $108(3.4)$ & $109(9.6)$ & $100(9.6)$ & $115(9.2)$ & $97(8.3)$ \\
\hline
\end{tabular}

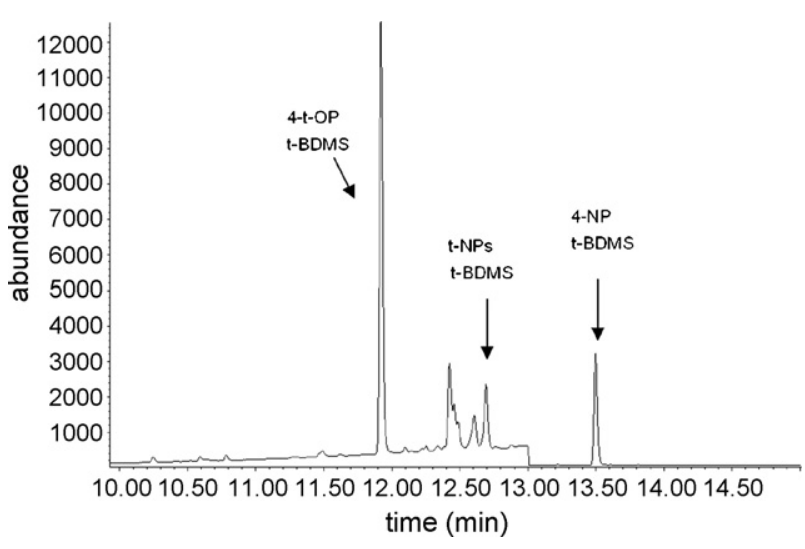

Fig. 3 - Typical GC/MS chromatograms of the t-BDMS derivatives from spiked samples in chlorinated tap water using headspace SPME with on-fiber derivatization. Sample volume was $2 \mathrm{~mL}$ and spiking level was $1 \mu \mathrm{g} \mathrm{L}^{-1}$. Peak of MTBSTFA not shown due to solvent delay.

ing time of headspace extraction for MTBSTFA was not necessary.

Various kinds of water samples, including detergent water, chlorinated tap water and lake water, were spiked with known amounts of APs to determine the precision and accuracy of the method developed (Table 2 shows the results). All the data from Table 2 met USEPA's $\pm 20 \%$ requirements [33]. As mentioned above, SPME fibers from two different batches were used for the tests on precision and accuracy, and the R.S.D. (shown in Table 2) indicates that the reproducibility of the batch-to-batch fibers in current study was within $100 \pm 10 \%$.

Besides SPME methods, traditional technique such as SPE has also been applied in the literature for the determination of APs from environmental samples [37,38]. However, SPE often requires large quantities of samples and solvents. For example, $20 \mathrm{~mL}$ of sample was needed to reach the MDL of $76 \mathrm{ngL}^{-1}$ for nonylphenol even when the derivatization with pentafluoropyridine was performed [37]. As shown in Table 3, the current method proposed MDLs were in the range of 1.58-3.85 $\mathrm{ng} \mathrm{L}^{-1}$ with only $2 \mathrm{~mL}$ of sample used.

As for the concentrations of APs in the environment, Ying et al. [4] summarized the findings from different researchers showing that the average levels of NP detected in surface waters ranging from 0.023 to $51 \mu \mathrm{gL}^{-1}$ worldwide. With the MDLs established in current study, lower concentrations of NP may be possible in future field investigations.

In Table 3, different SPME methods for the determination of APs in water were also compared. The current method can produce better sensitivities in measuring trace levels of APs in water samples. The possible reasons for the results were the unique procedures in this technique which included headspace extraction and derivatization with MTBSTFA. Since headspace extraction was performed instead of direct immersion, background adsorption and matrix effects were reduced. With derivatization, the quality and sensitivity of separations were also improved. Compared with other studies, derivatiza-

\section{Table 3 - Comparisons of different SPME methods for the analysis of APs in water}

\begin{tabular}{|c|c|c|c|c|c|}
\hline & Analytes & SPME mode & $\begin{array}{l}\text { Derivatization } \\
\text { reagent/mode }\end{array}$ & $\begin{array}{c}\text { Linear range and } \\
\text { MDLs }\end{array}$ & Ref. \\
\hline \multirow{4}{*}{$\begin{array}{l}\text { SPME without } \\
\text { derivatization }\end{array}$} & NP, NPnEO & Direct immersion & - & $0.11-2 \mu g L^{-1}$ & [20] \\
\hline & BrNPnEO & & & MDLs: $30-150 \mathrm{ng} \mathrm{L}^{-1}$ & \\
\hline & t-NPs, BPA & Direct immersion & - & $0.03-195 \mu g L^{-1}$ & [31] \\
\hline & $17 \alpha-\mathrm{EE}$ & & & MDLs: $20-200 \mathrm{ng} \mathrm{L}^{-1}$ & \\
\hline \multirow{4}{*}{$\begin{array}{l}\text { SPME with } \\
\text { derivatization }\end{array}$} & BPA, APs (BP, NP, OP) & Direct immersion & BSTFA/on-fiber & $0.5-50 \mu g \mathrm{~L}^{-1}$ & [15] \\
\hline & & & & MDLs: $2.2-14.1 \mathrm{ng} \mathrm{L}^{-1}$ & \\
\hline & $\begin{array}{l}\text { EDCs, steroid } \\
\text { hormone (OP, t-NP) }\end{array}$ & Direct immersion & BSTFA/on-fiber & $\begin{array}{l}0.01-100 \mu \mathrm{gL}^{-1} \\
\text { MDLs: } 3-72 \mathrm{ng} \mathrm{L}^{-1}\end{array}$ & [26] \\
\hline & $\begin{array}{l}\text { 4-t-OP } \\
\text { t-NPs, 4-NP }\end{array}$ & Headspace & $\begin{array}{l}\text { MTBSTFA with 1\% } \\
\text { TBDMCS/on-fiber }\end{array}$ & $\begin{array}{l}0.005-1.04 \mu \mathrm{gL}^{-1} \\
\text { MDLs: } 1.58-3.85 \mathrm{ng} \mathrm{L}^{-1}\end{array}$ & Current study \\
\hline
\end{tabular}


tion with MTBSTFA instead of BSTFA reduced the problems of hydrolysis.

\section{Conclusions}

This research focused on the development of analytical method for APs in water based on the technique of SPME with on-fiber derivatization. The $85 \mu \mathrm{m}$ PA fiber was used and a twostep sample preparation procedure was established. Water samples of $2 \mathrm{~mL}$ were first placed in a $4 \mathrm{~mL}$ PTFE-capped glass vial. Headspace extraction of APs in the water was then performed under $65^{\circ} \mathrm{C}$ for $30 \mathrm{~min}$ with $800 \mathrm{rpm}$ magnetic stirring and the addition of $5 \%$ of sodium chloride. Afterwards, the SPME fiber was placed in another $4 \mathrm{~mL}$ vial which contained $100 \mu \mathrm{L}$ of MTBSTFA with 1\% TBDMCS. During the procedure, headspace extraction of MTBSTFA and on-fiber derivatization with APs were performed at $45^{\circ} \mathrm{C}$ for $10 \mathrm{~min}$. GC/MS was then used for the analysis of derivatives formed on-fiber.

Compared with traditional methods, this method reduced and simplified the experimental procedure and omitted the use of organic solvents. Compared with other SPME methods, the on-fiber derivatization with MTBSTFA in this research provided an efficient analytical tool with better linear relationship, MDLs, precisions, and accuracy. The time saving procedure also makes the proposed method suitable for routine analysis of water samples.

\section{Acknowledgements}

This study was supported by grant from the Department of Health, Executive Yuan, Taiwan (DOH95-TD-F-113-026). The authors also acknowledge Dr. C.C. Chou from the Department of Veterinary Medicine, National Taiwan University, Taipei, Taiwan for his arrangements in the operation of GC/MS.

\section{REFERE NCES}

[1] European Commission Joint Research Center: European Union Risk Assessment Report, 4-Nonylphenol (branched) and Nonylphenol, 2nd Priority List, vol. 10, Luxembourg, 2002.

[2] R. Renner, Environ. Sci. Technol. 31 (1997) 316A-320A.

[3] G.G. Ying, Environ. Int. 32 (2006) 417.

[4] G.G. Ying, B. Williams, R. Kookana, Environ. Int. 28 (2002) 215.

[5] R.M. Harris, R.H. Waring, C.J. Kirk, P.J. Hughes, J. Biol. Chem. $275(2000) 159$.

[6] S.S. Madsen, S. Skovbolling, C. Nielsen, B. Korsgaard, Aquat. Toxicol. 68 (2004) 109.

[7] B. Gutendorf, J. Westendorf, Toxicology 166 (2001) 79.

[8] A.M. Soto, C. Sonnenschein, K.L. Chung, M.F. Fernandez, N. Olea, F.O. Serrano, Environ. Health Persp. 103 (1995) 113.

[9] EU Cement Directive: Directive 2003/53/EC of the European Parliament and of the Council, Official Journal of the European Union, Luxembourg, 2003.

[10] Y.C. Chin, L.L. Li, H.D. Wang, J. Chin. Chem. Soc. Taip. 52 (2005) 1257
[11] US Environmental Protection Agency: Aquatic Life Ambient Water Quality Criteria-Nonylphenol, US EPA-822-R-05-005, Washington, DC, 2005.

[12] Z. Xie, J. Selzer, R. Ebinghaus, A. Caba, W. Ruck, Anal. Chim. Acta 565 (2006) 198.

[13] C.Y. Cheng, C.Y. Wu, C.H. Wang, W.H. Ding, Chemosphere 65 (2006) 2275.

[14] X. Peng, Z. Wang, C. Yang, F. Chen, B. Mai, J. Chromatogr. A 1116 (2006) 51.

[15] C. Basheer, A. Parthiban, A. Jayaraman, H.K. Lee, S. Valiyaveettil, J. Chromatogr. A 1087 (2005) 274.

[16] J. Pawliszyn, Solid-Phase Microextraction - Theory and Practice, Wiley-VCH, New York, 1997.

[17] J. Pawliszyn (Ed.), Applications of Solid Phase Microextraction, Royal Society of Chemistry, Cambridge, 1999.

[18] J.A. Koziel, J. Pawliszyn, J. Air Waste Manage. Assoc. 51 (2001) 173.

[19] M. Llompart, K. Li, M. Fingas, J. Chromatogr. A 824 (1998) 53.

[20] A. Diaz, F. Ventura, M.T. Galceranb, J. Chromatogr. A 963 (2002) 159.

[21] J.B. Quintana, I. Rodriguez, Anal. Bioanal. Chem. 384 (2006) 1447.

[22] U. Bolz, W. Korner, H. Hagenmaier, Chemosphere 40 (2000) 929.

[23] H.B. Lee, T.E. Peart, Anal. Chem. 67 (1995) 1976.

[24] T.A. Ternes, M. Stumpf, J. Mueller, K. Haberer, R.D. Wilken, M. Servos, Sci. Total Environ. 225 (1999) 81.

[25] E.E. Stashenko, J.R. Martinez, Trends Anal. Chem. 23 (2004) 553.

[26] L. Yang, T. Luan, C. Lan, J. Chromatogr. A 1104 (2006) 23.

[27] A. Bouaid, L. Ramos, M.J. Gonzalez, P. Fernandez, C. Camara, J. Chromatogr. A 939 (2001) 13.

[28] D. Li, J. Park, J.R. Oh, Anal. Chem. 73 (2001) 3089.

[29] T. Racke, Determination of Estrogen-Active Nonylphenols and Octylphenol in Baby and Toddlers Food as well as in Biofilms, Doctoral Dissertation, Bonn University, Germany, 2004.

[30] A.M. Kvistad, E. Lundanes, T. Greibrokk, Chromatographia 48 (1998) 707.

[31] P. Braun, M. Moeder, St. Schrader, P. Popp, P. Kuschk, W. Engewald, J. Chromatogr. A 988 (2003) 41.

[32] CNS Standards 3800, Synthetic Detergent for Food and Kitchen Utensil, Bureau of Standards, Metrology and Inspection, MOEA, Taipei, Taiwan, 2000 (http://www. cnsonline.com.tw/en/preview/preview.jsp?general $\_$no $=0380000$ \&language $=C$ \&pagecount $=7$ ).

[33] US Environmental Protection Agency: Determination of Carbonyl Compounds in Drinking Water by Pentafluorobenzylhydroxylamine Derivatization and Capillary Gas Chromatography with Electron Capture Detection. Office of Research and Development, US EPA Method 556, Cincinnati, OH, 1998.

[34] P. Braun, M. Moeder, S. Schrader, P. Popp, P. Kuschk, W. Engewaldc, J. Chromatogr. A 988 (2003) 41.

[35] C. Dietz, J. Sanz, C. Camara, J. Chromatogr. A 1103 (2006) 183.

[36] K. Schoene, H.J. Bruckert, J. Steinhanses, A. Konig, Fresenius J. Anal. Chem. 348 (1994) 364.

[37] M. Kojima, N. Matsui, S. Tsunoi, M. Tanaka, J. Chromatogr. A 1078 (2005) 1.

[38] B.J. Yang, F.H. Jiang, X.Q. Xu, J.H. Chen, F. Lee, Chin. J. Anal. Chem. 35 (2007) 633. 